\title{
CRIANÇAS TUPINAMBÁ: RIOS, COLINAS, BANCOS DE AREIA E MATAS COMO LUGARES DO BRINCAR COTIDIANO
}

Léa Tiriba ${ }^{1}$

Christiana Cabicieri Profice ${ }^{2}$

INTRODUÇÃO

Nosso contato com os Tupinambá se deu em 2009, no contexto do Projeto "Tendências de políticas de transição em comunidades rurais, indígenas e de fronteiras” OEA/MEC/COEDI, cujo objetivo era compreender como as crianças indígenas vivenciam um cotidiano marcado pela transição entre espaços comunitários e espaços formais de Educação Infantil ${ }^{3}$. Considerando que comunidades educativas indígenas não podem ser substituídas por espaços escolares (BRASIL, sld), o estudo concluiu que o ingresso na educação infantil não constituía uma ruptura na tradição Tupinambá, pois se desenvolve no bojo de um forte movimento de resgate e afirmação da cultura e por direitos de cidadania. Em nossa compreensão, esta escola indígena tem um papel preponderante para o envolvimento das crianças e adolescentes com a afirmação do pertencer a uma determinada etnia. As educadoras Tupinambá assumem, então, protagonismo diante de uma escola a ser continuamente formulada, ainda que existam diretrizes nacionais especificas (BRASIL, 2012).

A partir deste estudo exploratório inicial, os Grupos GEPISA (Grupo de Estudos e Pesquisas das Interações Sócio Ambientais/UESC-BA) e GiTaKa (Grupo de Pesquisa Infâncias, Tradições Ancestrais e Cultura Ambiental/UNIRIO), em parceria com educadoras e lideranças indígenas, passaram a realizar uma pesquisa-intervenção que tem como foco a interação entre crianças e

\footnotetext{
${ }^{1}$ Docente e pesquisadora da Escola de Educação da Universidade Federal do Estado do Rio de Janeiro (UNIRIO). lea.tiriba@gmail.com

${ }^{2}$ Professora Titular da área de Psicologia do Departamento de Filosofia e Ciências Humanas da UESC, orientadora e docente do Programa de Pós-Grauação em Meio Ambientee Desenvolvimento Regional/PRODEMA

ccprofice@uesc.br

${ }^{3} \mathrm{O}$ projeto, que envolveu Brasil, Colômbia, Chile, Peru e Venezuela visou buscar conhecimentos e saberes teóricos e práticos que permitam apoiar os países membros da OEA em relação a elaboração e implementação de políticas que qualifiquem o cotidiano de crianças e seus professores em consonância com os modos de vida de suas comunidades. (TIRIBA, 2010)
} 
ambientes naturais, com o objetivo de acessar os sentimentos e os conhecimentos infantis acerca da natureza, bem como observar e promover atividades ao ar livre no período escolar.

Inicialmente, o texto faz uma breve apresentação dos povos Tupinambá de Olivença e do contexto sócio-político-ambiental em que se situam; e explicita as concepções filosóficas, políticas e ambientais que fundamentam o trabalho.

A seguir estão referências teórico-metodológicas de perspectiva etnográfica e análises de dados referentes às brincadeiras com a natureza, coletados desde 2009, com a participação de educadoras e estudantes de dez núcleos escolares do território Tupinambá. Trazemos para este trabalho fotografias e entrevistas realizadas com as crianças e educadores, além de notas de diário de bordo, partes de um extenso material que está ainda em análise. Nas considerações finais apostamos na possibilidade de que a pesquisa inspire e fundamente propostas escolares de desemparedamento que assegurem às crianças o direito de se manterem em conexão com o ambiente natural de que são parte; e que, num mesmo movimento, interroguem e superem a falsa premissa de divórcio entre seres humanos e natureza, que está na origem da crise socioambiental contemporânea.

\section{CENÁRIO TUPINAMBÁ E REFERÊNCIAS TEÓRICO-METODOLÓGICAS}

Os Tupinambá foram os primeiros indígenas a entrar em contato com os viajantes europeus que, no decorrer do século XVI, se surpreenderam com o modo de vida e com uma realidade cultural diferenciada, tanto em termos de costumes, quanto de organização política, rituais religiosos e educação (FÉLIX, 2008; NÖTZOLD, S/D). Os Tupinambá ocupavam um amplo território litorâneo das regiões dos atuais estados da Bahia, São Paulo e Rio de Janeiro e desempenharam um papel importante no processo de conquista e de colonização do litoral brasileiro. Suas aldeias eram economicamente autossuficientes, habitadas por 300 a 1000 pessoas que organizavam a produção e a sociedade a partir do trabalho coletivo. Até 1936, quando os coronéis do cacau construíram uma ponte entre Ilhéus e Olivença, os habitantes da região mantinham formas próprias de organização social e econômica. Em entrevista (informação verbal) ${ }^{4}$

\footnotetext{
${ }^{4}$ Nivalda Amaral de Jesus. Entrevista [28. nov. 2009]. Entrevistadora: Léa Tiriba, 2009. 1 arquivo digital. Entrevista concedida ao projeto "Tendências de políticas de transição em comunidades rurais, indígenas e de fronteiras" OEA/MEC/COEDI.
} 
de 28/11/2009, Nivalda Amaral de Jesus, cujo nome indígena é Amoatara (Amor) fala sobre como viviam:

Nivalda: Eu nasci, me criei, me casei aqui mesmo em Olivença. [...]tenho setenta e sete [anos]. Quando estava com dez anos vieram os coronéis [...]aí foi dizendo assim, olha: casa de palha não fica mais em Olivença e nem de taipa. As casas de todos aqui, todos os índios era de taipa e de palha.

Pesquisadora: Quem morava aqui antes disso?

Nivalda: Quem morava eram os índios, só índio que morava aqui. Aqui era aldeia.

Pesquisadora: E como era essa aldeia?

Nivalda: Era toda cheia de casinha. Não era assim no alinhamento não. Era casinha de palha ao redor da praça. Ali na praça era o cemitério que depois os jesuítas chegaram e tiraram o cemitério daí pra não ficar na praça. Mas tem ossos. Eles [os coronéis]chegaram e disseram [...] sua casa agora vai ficar de alvenaria porque aqui vai ser agora um lugar para turista. Vai ser lugar de veraneio.

Pesquisadora: Ficou algum índio por aqui?

Nivalda: Ficou nada, saíram tudo. [...]Foram expulsos. Eles davam três mil réis, uma cesta e um burro para carregar o que tinha, que num tinha quase nada. [...]A terra aí era da União, então todo mundo tinha suas pequenas roças, [...] botava mandioca, plantava abacaxi, era abobora e tudo, quando era dia de sábado trazia pra feira e trocava. Chegava aqui já tinha um peixe, trocava com alguém. Ninguém passava fome. Podia deixar o que fosse aí, ninguém roubava. Engraçado que a gente era feliz e num sabia, era feliz mesmo.

Após o massacre de $1937^{5}$, ocorrido às margens do rio Cururupe, onde a ponte seria construída, a lógica de organização coletiva e democrática desabou: os indígenas passaram a ocupar terras distantes do litoral e se tornaram trabalhadores das fazendas de cacau.

Hoje, cerca de 4.300 indígenas vivem em 23 comunidades, localizadas nos municípios baianos de Ilhéus, Buerarema e Una. Ao sul de Ilhéus, está a Aldeia Mãe de Olivença, situada sobre uma colina de onde se avista a beleza das praias com seus coqueirais.

Segundo lideranças, depois do reconhecimento da etnia como povo Tupinambá pelo governo federal, em 2002, eles têm sido constantemente demitidos. Esta situação é geradora de pobreza, e mesmo miséria, uma vez que as famílias não têm de onde retirar o seu sustento. Assim, a

\footnotetext{
${ }^{5}$ No dia 26 de setembro de 1937 aconteceu um grande massacre, conhecido pelos mais velhos como "A última revolta do Caboclo Marcelino". Nos últimos anos, a data passou a constituir-se como marco histórico, em que realizam a Marcha em Memória aos Mártires do Massacre do Rio Cururupe, considerada a única expressão pública de massa do Povo Tupinambá. O evento tem o intuito de somar forças em prol da demarcação das terras e de dizer não à violência praticada contra os Tupinambá de Olivença.
} 
organização, as lutas, as reivindicações estão relacionadas à movimentos de retomada e de demarcação de terras que consideram como de sua propriedade, o que vem gerando uma situação de tensão, especialmente na relação com os fazendeiros da região. Ainda não definitivamente homologada pelo governo federal, a demarcação da terra indígena Tupinambá de Olivença não se conclui, o que certamente é um fator que interfere diretamente na rotina das escolas.

Estas informações sobre o contexto mais geral são fundamentais para a pesquisa porque todo o processo de estruturação da Educação Infantil indígena é fruto e se desenvolve no bojo de um forte movimento de resgate da história dos Tupinambá. Como se pode perceber no depoimento abaixo, a luta pela educação está relacionada à necessidade de afirmação da identidade indígena e à luta por direitos de cidadania.

Cristiane: Não existia escola indígena aqui e [...] gente não vivia no movimento indígena, [...]por causa do massacre que teve no Cururupe e isso fez com que o nosso povo se dividisse. Muitos foram pra dentro das matas onde alguns ainda moram, outros ficaram aqui em Olivença e outros foram morar pra Ilhéus. [...]depois Dona Nivalda junto com a pastoral da criança e outro grupo de professores foi falando, foram nas comunidades dizendo pra gente 'olha vocês são índios, são da etnia tupinambá' e ai a gente começou o movimento indígena. (Informação verbal) 6

Num contexto de afirmação de modos de pensar e viver que são próprios, os sujeitos/o grupo afirmam seus direitos de etnia, enfatizando a cultura nativa como referência para a sua inclusão no meio socialmente letrado.

Animadas pela energia potente das crianças, das educadoras e das lideranças locais, passamos acompanhar mais de perto as atividades com as crianças e de formação das educadoras, com vistas à produção coletiva de uma pedagogia comprometida com a reafirmação de sentimentos de pertencimento étnico de meninos e meninas indígenas, como prevê o Art. $7^{\circ}, \S 2^{\circ}$, das Diretrizes Curriculares Nacionais da Educação Infantil (BRASIL, 2009); e, da mesma forma, comprometida com “a interação, o cuidado, a preservação e o conhecimento da biodiversidade e da sustentabilidade da vida na Terra, assim como o não desperdício dos recursos naturais", como está no Art. $9^{\circ}$, item X das DCNEI.

${ }^{6}$ Crys Amanary Tupinambá. Professora Núcleo Katuana: Depoimento [26.nov.2010]. Entrevistadora: Léa Tiriba. Educação infantil entre os povos Tupinambá de Olivença. Relatório Final, 2010. 1 arquivo digital. Entrevista concedida ao projeto "Tendências de políticas de transição em comunidades rurais, indígenas e de fronteiras" OEA/MEC/COEDI. 
É na perspectiva destas definições legais que desenvolvemos, desde 2011, um trabalho de assessoria aos núcleos de Educação Infantil Tupinambá de Olivença. Na mesma direção, o projeto de ensino "Educação ambiental em comunidades tradicionais" é desenvolvido na Universidade Estadual de Santa Cruz/UESC e conta com a presença de seus bolsistas no Núcleo Katuana.

Em busca de conceitos que funcionem como instrumentos de provocação e questionamento da realidade e com vistas às transformações que desejamos fomentar, definimos a ideia de equilíbrio ecosófico como conceito ferramenta que possibilita perguntar sobre a realidade de hoje e também invocar e desafiar para além (GALLO, 2003). O conceito de ecosofia, formulado por Guattari (1990) articula três ecologias: pessoal ${ }^{7}$, social e ambiental.

\begin{abstract}
A ecologia pessoal diz respeito à qualidade das relações de cada ser humano consigo mesmo; a ecologia social está relacionada à qualidade das relações dos seres humanos entre si; e a ecologia ambiental diz respeito às relações dos seres humanos com a natureza. (TIRIBA, 2005, p.23)
\end{abstract}

Em sua articulação, estes registros ecológicos condensam as dimensões da existência. Eles definem equilíbrios que expressam a qualidade de vida sobre a Terra, a nos planos local e planetário. De fato, tendo como referência a realidade do mundo, o conceito de ecosofia possibilita olhar para o cotidiano das crianças nas instituições de Educação Infantil, e perguntar: como vão as relações de cada criança consigo mesma? Qual a qualidade das relações entre os humanos que constituem a comunidade escolar? E como vão as relações destes com a natureza? No transcorrer da existência cotidiana de crianças e adultos, qual a qualidade deste amálgama de relações? (TIRIBA, 2005)

Consideramos que as crianças se constituem na cultura e são produtoras de culturas (VYGOTSKY, 1989). Entretanto, entendemos que os humanos são, simultaneamente, seres da cultura e seres da natureza. Seu desenvolvimento se dá na interação com os membros de uma espécie que possui especificidade histórica, cultural, racional, linguística e política (LOUREIRO, 2006; GUIMARÃES, 2006). Mas elas só se constituirão integralmente se forem sujeitos de seus corpos em conexão com elementos que as afetam: a água, a terra, a areia, os ventos, o sol... Assim,

\footnotetext{
${ }^{7}$ Sem prejuízo ao conceito de ecologia mental, trabalhado por Félix Guattari, em "As três ecologias", adotamos a expressão "ecologia pessoal”, por sua abrangência e por apontar para a superação do dualismo corpo/mente.
} 
as crianças são seres que se constituem em conexão com outros seres, humanos e não-humanos, e se potencializam neste estado de conexão (ESPINOSA, 1983).

Em acordo com este filósofo do século XVII, a natureza é a substância única de que todas as coisas são modos de expressão. Ela é o "princípio ativo que anima e movimenta os seres. [...]força espontânea capaz de gerar e de cuidar de todos os seres por ela criados e movidos" (CHAUÍ, 2001, p. 209). É a substancia presente em todas as coisas e em todos os seres que compõem o cosmo. Como na filosofia dos pré-socráticos (BORNHEIM, 2001), a Natureza é a própria Vida, em suas manifestações físico-afetivas. Como para Rousseau, ela não é essencialmente matéria e movimento mecânico, mas "palpita dentro de cada ser humano como íntimo sentimento de vida" (CHAUÍ, 1978, p. XVI).

Se todos os seres são modos de expressão da natureza e estão entrelaçados com outros modos, tudo está em rede, os seres afetam e são afetados, “o exercício de sua potência será, em grande parte condicionado pelos encontros oriundos desse entrelaçamento" (GLEIZER, 2005, p.13). Daí a paixão que as crianças manifestam pela vida ao ar livre!

Definindo-as como modos de expressão da natureza cuja existência se dá em conexão com outros modos, pensamos, com Espinosa, que o impulso que as leva a buscarem a proximidade com o mundo natural se deve ao fato de afetarem e serem afetadas pelos demais modos: pelos elementos da cultura, mas também por elementos do mundo natural com os quais estão estruturalmente acopladas (MATURANA, 2002). As crianças se lançam à natureza porque sua potência de agir as move para a realização de bons encontros; pois, como todos os seres vivos, estar nela lhes assegura permanecerem sendo o que são, sendo o que as constitui.

Entendendo os ambientes naturais como aqueles que todos os seres compartilham, aí incluindo humanos e não humanos, como também componentes e processos físicos como o ar, as montanhas e os fenômenos climáticos (TIRIBA; PROFICE, 2014), e considerando os humanos como indissociáveis do ambiente, chegamos ao conceito de biofilia. Este conceito, referência nos estudos pessoa-ambiente, diz respeito a uma tendência à união, a um senso de pertencimento com o mundo natural e seus seres (KELLERT \& WILSON, 1993; PROFICE, 2010; 2016).

A biofilia é uma condição em relação à qual todos os seres vivos coincidem: o vivo segue em direção ao vivo porque se reconhece nele. Assim, as crianças, ao lançarem-se à natureza, afirmam a sua condição biofílica. Ao contrário, em ambientes emparedados elas são privadas desta conexão fundamental à sua integridade. Se as sociedades retiram a natureza de seus espaços de 
vida, as crianças têm sua biofilia interrompida, o que acreditamos trazer enormes comprometimentos ao seu desenvolvimento, saúde e bem-estar.

Oriundo dos estudos pessoa-ambiente, outro conceito que orienta a pesquisa é o de apego ao lugar (CHAWLA, 1992). O apego ao lugar nos diz do apreço que se tem por uma dada localidade, da existência de vínculos afetivos positivos com um determinado ambiente e o bem-estar nele experimentado. A teoria do apego foi inicialmente desenvolvida na psicologia para entender como se estabeleciam os vínculos afetivos entre as pessoas, sobretudo entre crianças e seus pais e cuidadores. O apego ao lugar trata do vínculo estabelecido entre a pessoa ou grupo com lugares específicos, seus elementos e também com os seres vivos e pessoas que nele interagem. De um lugar nos fica uma vivência em memória, um cheiro, um som, uma luz, uma sensação de bem estar e segurança ou de inquietude e medo. Todas as dimensões do ambiente contribuem para o apego que se tem de a um lugar, para o sentido que este lugar tem para cada um e para o significado que é compartilhado na comunidade.

Como vimos, nosso apego ao mundo natural foi conceituado como biofilia (KELLERT \& WILSON, 1993). A biofilia é o apego que temos ao mundo natural, dado que somos seres vivos e nossa sobrevivência depende do modo como interagimos com os demais seres vivos e participamos dos processos naturais como corpos naturais. A biofilia move as crianças na direção dos seres vivos e dos elementos naturais do ambiente, mas hoje os ambientes de desenvolvimento humano são cada vez mais emparedados e desprovidos de natureza. Esta é a realidade que nos desafia.

Esta realidade se afastamento em relação ao mundo natural é uma das consequências da visão moderna de mundo, que se assenta em uma concepção ontológica da natureza como racionalmente organizada; que, epistemologicamente, se apoia na ideia da razão como instrumento de abordagem e compreensão da realidade; e, finalmente, se sustenta na concepção antropológica de um ser humano definido por sua atividade mental (PLASTINO, 2001). Desenhada num contexto de desenvolvimento da utopia capitalista, a instituição escolar dos dias de hoje está ainda fundada nesses pressupostos (FORMOSINHO, 1998). Como a Base Nacional Comum Curricular/BNCC evidencia, os objetivos, conteúdos e formas de organização de espaços e tempos ignoram perspectivas ontológicas, epistemológicas e antropológicas afirmadas por outras filosofias, outros modos de pensar e sentir a vida, entre elas, as dos povos e comunidades tradicionais da América Latina e do Caribe (FLORES; TIRIBA, 2017).

Entendendo que as crianças perseveram em seu movimento brincante porque as brincadeiras se dão no contexto e qualificam a expressão ecosófica que é fruto da articulação entre três ecologias 
(pessoal, social e ambiental), estamos interessadas nas relações que professoras e crianças estabelecem com a natureza. Porque, se os pequenos gostam de estar ao ar livre, é porque aí realizam bons encontros, e, portanto, vivenciam paixões alegres, sentem-se mais felizes, ganham potência (ESPINOSA, 1983; DELEUZE, 2002). Em interação com um universo que é mais amplo, que vai além das paredes das salas, aprenderão com alegria. E se a qualidade das aprendizagens é proporcional à qualidade das interações, então as crianças aprenderão melhor quando estiverem mais felizes, e cabe às instituições de educação infantil se empenharem na oferta de tempos e espaços que favoreçam a sensação de realização, de plenitude, de inteireza de corpo e espírito.

É com base nas ideias acima expostas que analisamos observações registradas em diário de campo e através de fotografia e filmagem de atividades conduzidas pelas educadoras indígenas nos ambientes naturais do entorno das escolas. A coleta de informações se fez, desde 2009, através de técnicas qualitativas, como observação participante e entrevistas individuais e coletivas gravadas, com crianças, professoras, familiares e lideranças locais em diferentes oportunidades e espaços.

No mapa abaixo estão localizadas as aldeias dos Tupinambá de Olivença e, em destaque, as unidades visitadas, todas vinculadas à Escola Sede, que articula e coordena o trabalho de educação escolar indígena desenvolvido na região, sob a responsabilidade do governo do Estado da Bahia, com o apoio da FUNAI.

FIGURA 1 - MAPA DA TERRA INDÍGENA TUPINAMBÁ DE OLIVENÇA COM INDICAÇÃO DAS ESCOLAS VISITADAS.

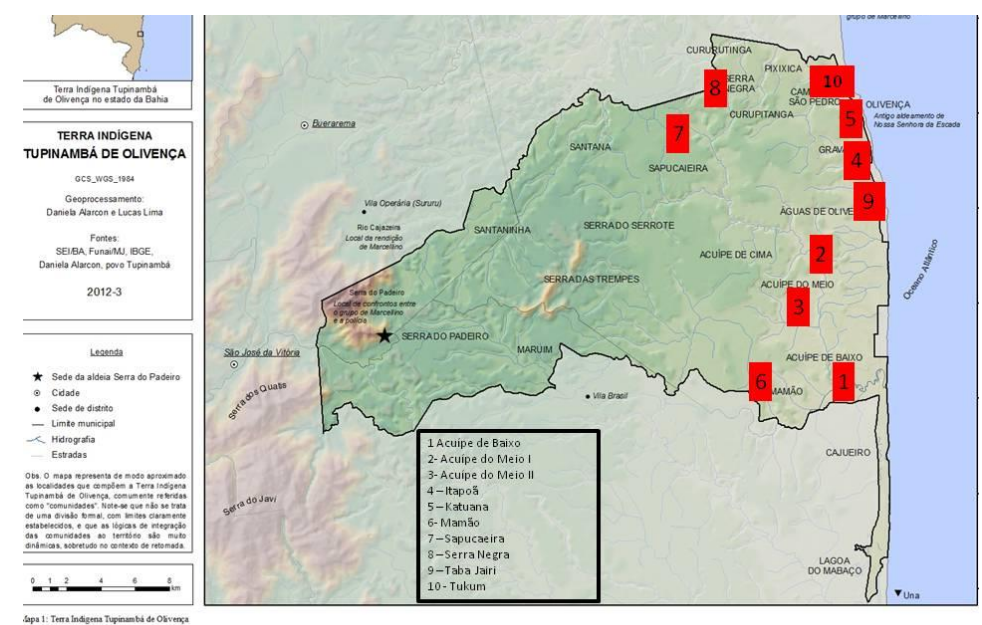

Fonte: Diário Oficial, (20/04/2009).

Mapa da delimitação da TI Tupinambá de Olivença 
O estudo tem vínculos com uma perspectiva etnográfica em que o observador é parte integrante do objeto de estudo, afeta e é afetado. Pois, como afirma Geertz (1989), o etnógrafo não estuda os lugares, mas nos lugares.

O esforço de desestranhar o alheio permitiu desnaturalizar e questionar o que é conhecido. Neste caso, conhecidos são espaços, rotinas e práticas de Educação Infantil próprias do modo ocidental de organização social. Frente à realidade Tupinambá, como interpretar o prato de sopa servido no chão? Seria falta de estrutura (ausência de mesas e toalhas), desconhecimento das professoras quanto á normas de higiene, desleixo ou, simplesmente, um costume Tupinambá? Na busca de respostas foi necessário ter em conta que:

[...] o formato que conhecemos internacionalmente de Educação Infantil, evidentemente com variações especialmente em termos de qualidade, é originário das sociedades européias em urbanas, tendo sido constituído para responder a necessidades/interesses das sociedades européias modernas e daquelas que seguem este modelo (ROSEMBERG, s/d, p.19)

Enquanto assessoras, trabalhando na perspectiva da pesquisa-intervenção (BARROS, 1994), frente a praticas educativas tupinambá - diferenciadas em alguns aspectos, se considerarmos o modelo europeu, mas também reprodutoras deste mesmo modelo - atuamos atentas à linhas de fuga ao que se constituiu como hegemônico.

Como manter-nos sensíveis e abertas ao que se mostra estranho, como potencializar brechas no que é dominante? Como considerar o que é visível como um campo de possibilidades, em que estão postas também as alternativas ao que está empiricamente dado. Como considerar que se mostra, não o que falta?

$\mathrm{Na}$ busca de respostas a estas questões, um caminho muito produtivo é o confronto dos entrevistados com os resultados obtidos em fases anteriores. Esta estratégia de trabalho possibilita a confirmação e/ou a negação, ou mesmo fez emergir uma conflitualidade frente aos dados apresentados. Em qualquer das hipóteses, exige novas posturas das investigadoras; e, sem dúvida, sobre as pesquisadas, o efeito é o de uma prática de intervenção, uma vez que provoca questionamentos sobre suas concepções e práticas de trabalho. Na perspectiva da pesquisa intervenção, o objetivo não é compreender a ação, apenas, mas impulsioná-la em desenvolvimento, numa perspectiva de qualificação do trabalho que já é realizado. 
BRINCADEIRAS COM A NATUREZA

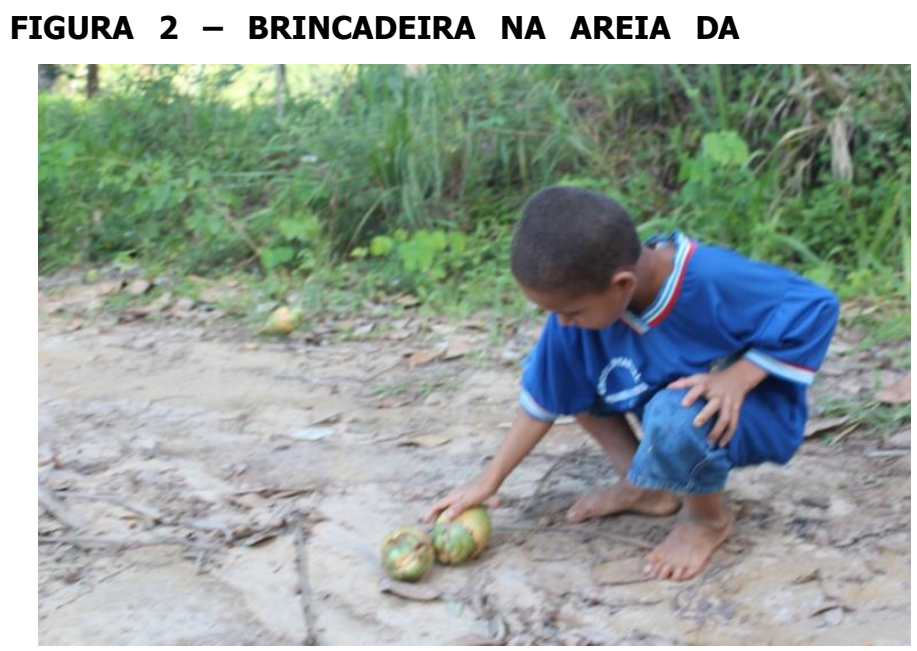

Fonte: Projeto Infâncias Tupinambás, (2012)

Subvertendo o modelo ocidental de organização escolar, as crianças da Creche Katuana saem quase todos os dias para caminhar por Olivença: elas lancham na mata, brincam na praça central, vão à praia e ao balneário de Tororomba tomar banho de piscina... Rios, colinas, bancos de areia e matas são os lugares do brincar cotidiano.

Desse modo, a escola as reinsere no universo que é por elas conhecido. Numa das tardes, acompanhamos a turma que sai da escola após o lanche:

São cerca de 25 crianças acompanhadas por 5 adultos. Seguimos pela calçada, descemos ladeiras e escadarias, atravessamos a pista à beira mar. O combinado é que iríamos para a quadra de esportes situada na areia da praia, cimentada e gradeada. Mas, logo depois, algumas crianças deslocam-se para a areia, procuram conchas, fazem buracos, aproximam-se do mar. Um menino entra na água de roupa e tudo, e depois rola na areia, os adultos não reclamam. Aos poucos, outras crianças vão saindo da quadra e se aproximando do mar, colocam os pés, as pernas, o corpo inteiro na água. Os adultos acompanham. Uma menina pede para ser enterrada na areia, a professora vai cobrindo e cantando, referindo-se a cada parte do corpo. Outros também querem, ela vai atendendo. Não há uma proposta para cada um ou para o grupo, uns estão na areia brincando, outros à beira d’água. Os adultos, atentos, se divertem junto com as crianças, não reclamam, não interferem, a não ser em situação de perigo. (DIÁRIO DE CAMPO, abr. 2010). ${ }^{8}$ 
Transborda sensibilidade dos adultos em relação aos movimentos infantis: em função dos interesses que vão surgindo o objetivo pedagógico inicial é redefinido permanentemente. É visível a disponibilidade para seguir as crianças em seu movimento de busca de conexão com o ambiente natural.

Destacamos a autonomia de movimentação de meninos e meninas Tupinambá: elas circulam em grupos ou mesmo sozinhas pelo território, os grandes cuidando dos pequenos, manuseando instrumentos que não são comuns nas mãos das crianças urbanas, como facas e facões.

Nas aldeias ou à beira-mar as crianças brincam de cavalo de pau, de empurrar roda de pneu com pedaço de arame, de jogar futebol. Elas criam estradas, pontes, montanhas, castelos. Na areia constroem parques em que os elementos variam de acordo com a temática que desejam. Brincam à beira do mar ou nos riachos que ai deságuam: correm das ondas, pegam “jacaré”, lambuzam-se de areia, nadam, inventam muitos modos de mergulho. Imitam as lutas dos pais que treinam para os jogos indígenas, organizam corridas, ensaiam "saltos mortais” nas pinguelas sobre os riachos que deságuam na praia.

\section{FIGURA 3 - BRINCADEIRA NA AREIA, CABANA \\ DO RIO, PRAIA DE OLIVENÇA.}

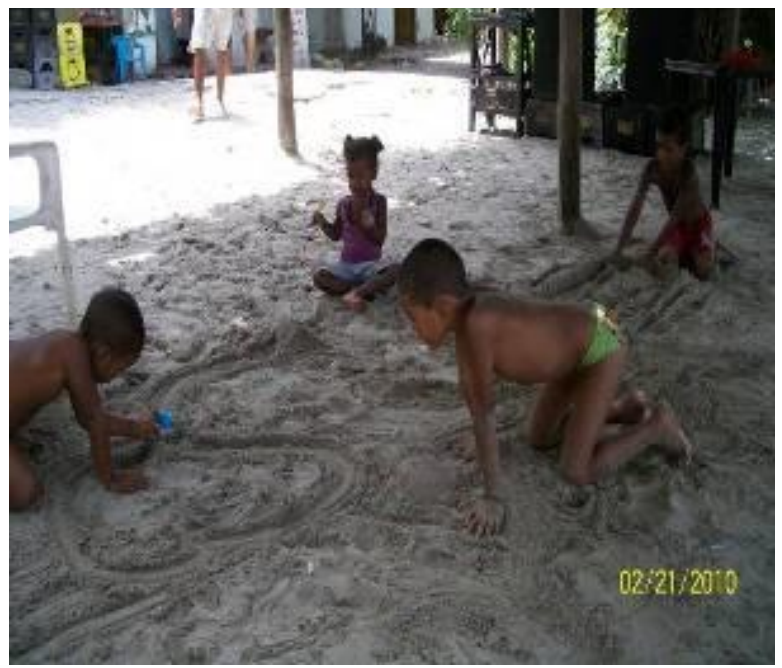

${ }^{8}$ Informação extraída de diário de campo. Pesquisadora: TIRIBA. Educação infantil entre os povos Tupinambá de Olivença. Relatório Final. 2010. Projeto "Tendências de políticas de transição em comunidades rurais, indígenas e de fronteiras" OEA/MEC/COEDI. 
Fonte: Maria Carolina Santana, (2010)

FIGURA 4 - BRINCADEIRA NA ÁGUA, OLIVENÇA.

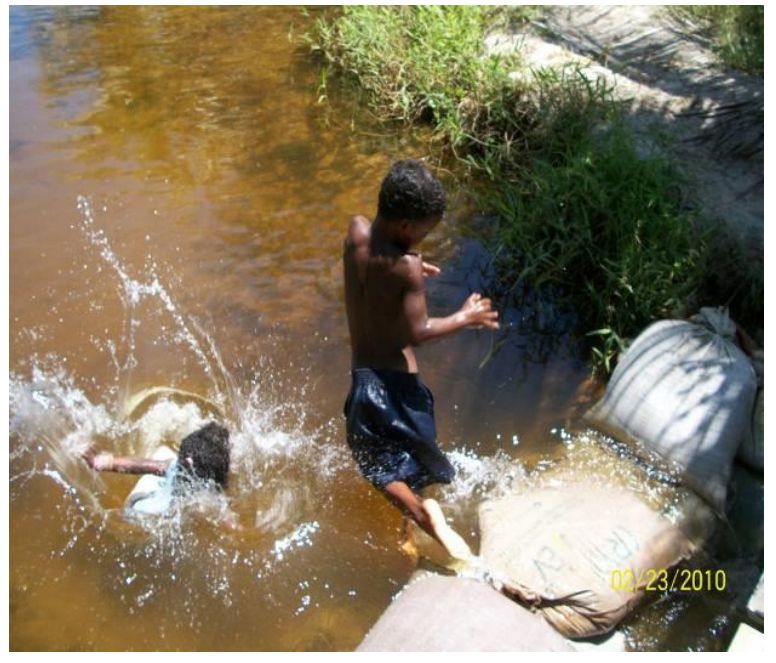

Fonte: Maria Carolina Santana, (2010).

Atentas às suas brincadeiras, pode-se conhecer os saberes de crianças ainda muito pequenas, como é o caso de Carolina, menina de 3 anos que frequenta a creche do Núcleo Katuana. Numa das manhãs ela está brincando na areia, com o irmão de 1 ano e 3 meses. Tem nas mãos uma garrafa pet cortada ao meio, dentro está um caranguejinho desses de areia, todo branco. Tira o bichinho do pote, conversa com ele, põe na areia pra passear e depois recolhe, faz isto várias vezes. Ela tem habilidade, não se deixa picar pelo bicho, nem o machuca. Abaixo, o diálogo estabelecido entre Carolina e a Pesquisadora.

Pesquisadora: Carol, onde o caranguejinho mora?

Carolina: Não é caranguejinho, é um "grossá”. Ele mora embaixo da areia, eu boto água no buraco que ele sai”

Pesquisadora: Quem ensinou você a pegar o grossá?

Carolina: Eu sozinha, fui eu que ensinei sozinha[...]Ele não morde porque eu pego de traz. Eu pego porque eu quero brincar!

Pesquisadora: E você não machuca ele?

Carolina: Não machuco, ele tem mãe [coloca o bichinho na areia e mexe no buraco]. A mãe do grossá mora longe. (CADERNO DE CAMPO 1, p. 33, abr. 2010) 9 
FIGURA 5 -BRINCADEIRA NA AREIA - CABANA DO RIO, PRAIA DE OLIVENÇA.

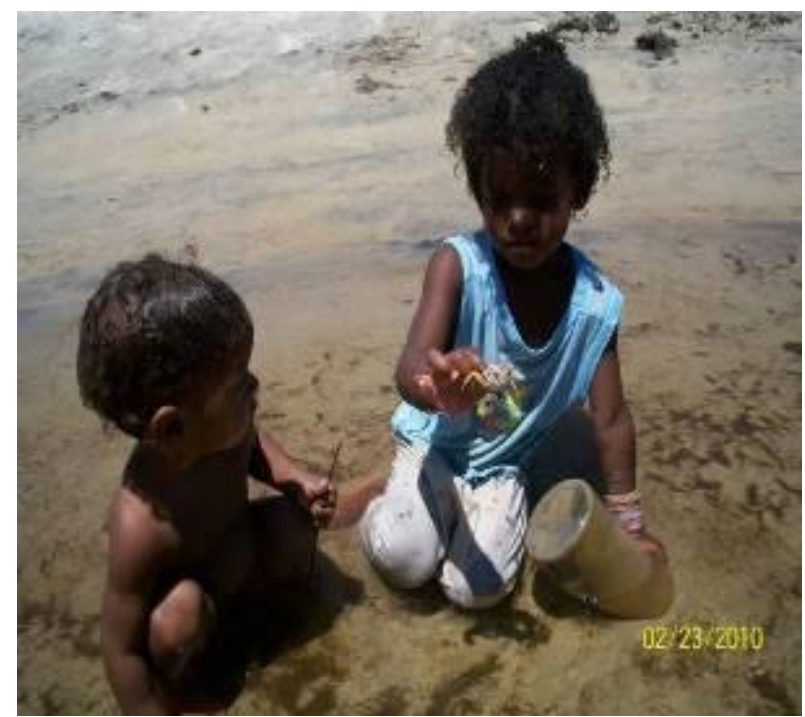

Fonte: Maria Carolina Santana, (2010)

Ao estabelecermos um paralelo entre a infância Tupinambá atual e aquela do século XVI descrita por Florestan Fernandes (1975), a partir do relato de cronistas da época, podemos certamente observar rupturas em tantos aspectos culturais que identificamos como o que o caracteriza um povo: sua língua, suas vestimentas, seu universo material e imaterial, seus rituais e cosmogonia. De fato, o tupi não é dominado pela comunidade Tupinambá. Apesar de valorosos esforços de universidades estaduais em promover o aprendizado do tupi entre os educadores, estes não dominam a língua, ainda que o bilinguismo seja um dos aspectos fundamentais da educação escolar indígena (BRASIL, 2012).

Contudo, foi possível detectar proximidades entre a infância Tupinambá atual e aquela do século XVI. Conforme Fernandes (1975, p.9), a criança aprende brincando e o brinquedo é o instrumento de trabalho do pai ou da mãe. E posteriormente "o índio que brincou de trabalhar vai trabalhar brincando".

Em seus depoimentos, as educadoras indígenas afirmam que, em suas infâncias, brincavam entre si e com os adultos, ao ar livre ou dentro de casa, por meio de rodas e cantigas, algumas em

\footnotetext{
${ }^{9}$ Informação extraída de diário de campo. Pesquisadora: L.,Tiriba. Educação infantil entre os povos Tupinambá de Olivença. Relatório Final. 2010. Projeto "Tendências de políticas de transição em comunidades rurais, indígenas e de fronteiras" OEA/MEC/COEDI.
} 
tupi (SANTOS, ALMEIDA \& PROFICE, 2014). Destacamos o extrato de uma entrevista (Informação verbal $)^{10}$ realizada com a educadora Jacira de 40 anos.

Jacira: Fazíamos casinhas de palhas, os meninos responsáveis por cortar as madeiras e as meninas catarem as palhas. Depois juntávamos, todos juntos, o barro, as madeiras e as palhas, e montávamos as paredes $e$ o teto. [...] além desta da casinha, tínhamos as canções e brincadeiras de roda nos dias de lua cheia [...]Cantávamos para Jacy em tupi [...] esta canção é umas das poucas cantadas em nossa língua mãe.

[Jacyaeaendejacy [...] Mbaepemoindyiande taba [...]Tupã ourtym. Isapeiandé taba. Tradução: Jacy é a nossa lua [...]. Que clareia a nossa aldeia [...]Tupã venha arramiá, iluminar a nossa aldeia. ]

[...]. Tínhamos o costume de brincar de roda durante a lua cheia, onde recontávamos as histórias e poesias que ouvíamos de nossos pais. Quando não era lua cheia, ficávamos dentro de casa tomando "giróba" [bebida feita de mandioca] e ouvindo histórias contadas pelos pais, sobre onça, cobra pico de jaca e outros animais da mata. [...] contavam como proteger a roça destes bichos e também de nos proteger... se sentíssemos o cheiro de cabaça [fruta da região] tínhamos de sair ligeiro... era sinal de onça. Já com a cobra pico de jaca...era o cheiro da jaca [fruta da região] daí que vem o nome do bicho, ela gosta de ficar perto desses pé de planta [sic] (SANTOS, ALMEIDA \& PROFICE, 2014, p.267-268).

O depoimento de Jacira evidencia, nas brincadeiras de crianças das atuais professoras, a forte interconexão entre cultura e natureza: barro e casa, lua e ciranda, onça e roça. Ainda hoje, muitas dessas brincadeiras, histórias e poesias estão presentes na vida das crianças Tupinambá.

Ainda que já estejam presentes brinquedos industrializados e dispositivos eletrônicos, o senso de pertencimento biofílico é bastante alimentado nas atividades escolares cotidianas, por meio de suas brincadeiras com elementos do ambiente natural. De fato, raramente as crianças dispõem de brinquedos fabricados!

Professora: [...] algumas a família tem dinheiro e compra na loja, mas a maior parte não pode, então inventa a brincadeira com o que tem.

\footnotetext{
${ }^{10}$ Jacira, educadora indígena: Entrevista. [nov. 2013]. Entrevistadores: G.M., Santos; N.M. Almeida. 1 arquivo digital. Entrevista concedida ao Projeto Infâncias Tupinambás: estudo de caso da interação entre crianças e ambientes naturais em comunidades indígenas.
} 
[...] as bonecas são de tronco de árvore, palha de coco e pedaço de pau. [...] Mainha fazia roupinha de pano, tira velha, a gente vestia a roupa nelas. (Informação verbal)11

Na dinâmica da creche, como das casas e dos locais públicos onde brincam, os brinquedos fabricados não se constituem como elementos fundamentais. Não se afirma, com isto, que não deveriam estar presentes, mas, simplesmente, que as rotinas infantis se organizam em atividades e brincadeiras em que utilizam os próprios corpos, em rodas, cantorias, conversas, muitas vezes em conexão com elementos e fenômenos da natureza, como os movimentos das águas no riacho, conchas, gravetos, sementes. Aí elas se divertem, aprendem entre si, trocam informações, definem papéis, se organizam.

FIGURA 6 - CRIANÇAS BRINCANDO EM ESPAÇOS NATURAIS

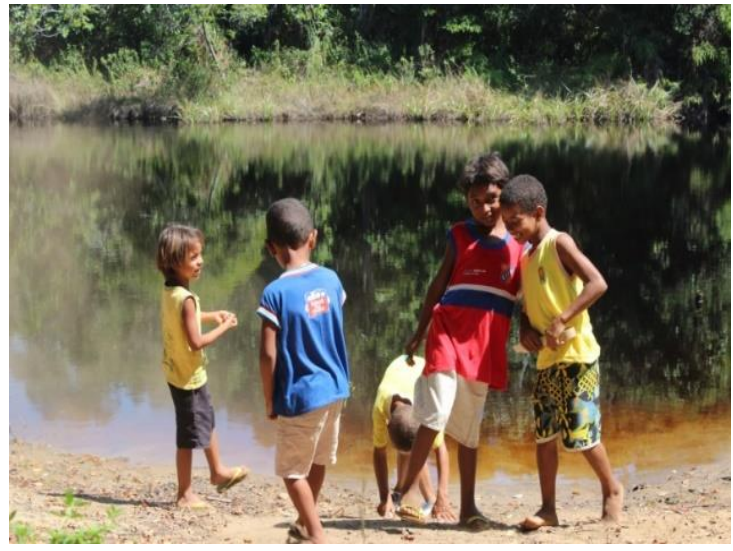

Fonte: Projeto Infâncias Tupinambás, (2012)

\section{CONSIDERAÇÕES FINAIS}

A pesquisa sobre concepções e práticas de educação de crianças indígenas em espaços institucionalizados revela que a pedagogia Tupinambá alimenta apego à natureza do lugar em que vivem. Assim, podemos dizer, com Boaventura de Sousa Santos (2001), que, entre os Tupinambá de Olivença, há resíduos que sobrevivem, evidentes nos modos pelos quais adultos e crianças se relacionam entre si e com o ambiente natural.

\footnotetext{
${ }^{11}$ Jacira, educadora indígena: Entrevista. [nov. 2013]. Entrevistadores: G.M., Santos; N.M. Almeidal arquivo digital. Entrevista concedida ao Projeto Infâncias Tupinambás: estudo de caso da interação entre crianças e ambientes naturais em comunidades indígenas.
} 
Consideramos que a experiência de educação infantil Tupinambá pode servir de inspiração para as escolas da cidade porque esta liberdade e segurança já não constituem o cotidiano das crianças urbanas, que passam a maior parte do tempo em ambientes fechados e controlados por adultos que determinam onipresentemente o que deve ser feito por elas e por seus educadores. Impedidas de brincar onde historicamente os humanos brincaram e se constituíram, creches e préescolas reproduzem relações entre o modelo de desenvolvimento que submete a natureza e o modelo de funcionamento escolar que submete o corpo humano.

Neste contexto, propomos reintegração ao universo do qual somos parte através de um movimento de desemparedamento, que precisa ser realizado, não apenas por consideração às demais espécies, mas também pela necessidade de preservação da própria espécie humana.

Se entendermos que nós, humanos, somos seres da natureza e que nosso pleno desenvolvimento depende diretamente da vivência dos vínculos com os demais seres e processos vivos, podemos fazer avançar a ideia de que vivemos em tempos de uma biofilia interrompida.

Como vimos, anteriormente, a biofilia é um conceito que nos diz de nosso pertencimento ao mundo vivo, à inclinação a interagir com os seres da natureza, em direção a bons encontros (ESPINOSA, 1983). De fato, nos sentimos bem, aliviamos o estresse quando estamos fora de ambientes confinados. Assim, a perseverança das crianças, o movimento infantil insistente de busca de bons encontros com o ambiente que está para além das paredes, se dá pela necessidade e pelo prazer que esse contato propicia, pois é evidente que, “[...] não apetecemos nem desejamos uma coisa porque a consideramos boa, mas, ao contrário, julgamos que uma coisa é boa porque tendemos para ela [...] e a desejamos" (ESPINOSA, 1983, p.182).

Podemos então compreender o grande desserviço que prestamos às crianças ao estabelecermos um cotidiano com raras oportunidades de interação com a natureza. Nós coevoluimos com as demais espécies do planeta e com elas nos tornamos humanos e desenvolvemos nossa capacidade de empatia e altruísmo. Fora da natureza nos vemos comprometidos em nossa própria humanidade. Sem a chance de interagir com os seres da natureza, as pessoas, e especialmente as crianças têm pouca possibilidade de desenvolver uma bioética que considere o direito à vida como um valor intrínseco, de proteger a existência dos demais seres vivos independente de sua serventia para as pessoas. A visão antropocêntrica de que a natureza é recurso, a desvitaliza, retira-lhe o caráter sagrado, de bem que existe como dádiva para todos, para transformá-la em simples fonte de matérias-primas e serviços para os seres humanos (SILVA; 
TIRIBA, 2014). Essa visão se estende, pois, aos próprios humanos, conformando relações imediatistas e utilitaristas.

Estas são as lições que ensinamos nas escolas, quando supervalorizamos o aprendizado de conteúdos descolados de nossa corporalidade e de nossos sentimentos, quando valorizamos o sucesso individual em detrimento do coletivo e, sobretudo, quando decidimos, de modo antropocêntrico e adultocêntrico, o que é melhor para as crianças. Se elas não se adaptam à escola, isto não é disfunção, é um grito de socorro que tentamos sufocar com psicopedagogias e ritalinas.

Assim como a natureza, as crianças resistem, dentro e fora de nós. Sua paixão pela natureza expressa a necessidade de se manterem em conexão.

Contudo, não se trata de negar nossa condição de humanos como seres produzidos na e pela cultura (VYGOTSKY, 1989). Ao contrário, o que os estudos Tupinambá evidenciam é a possibilidade de resgatar, afirmar e associar a condição biofílica à condição cultural. Para tanto, no plano das concepções, o caminho é o de superar a falsa premissa paradigmática que divorcia seres humanos e natureza. E, no plano das práticas cotidianas, desemparedar e acompanhar as crianças em seu movimento de encontro com a vida. A leitura do que está para além das paredes exige a abertura de portas de acesso a dimensões humanas que a educação escolar, em geral, desqualifica, como a corporal, a artística, a espiritual, a cosmológica. A conexão com a natureza abrirá essas portas!

\section{REFERÊNCIAS}

BARROS, Regina Benevides de. Grupo: a afirmação de um simulacro. Porto Alegre: Sulina/Editora da UFRGS, 2009 - (Coleção Cartografias) 350 p. ISBN

BRASIL. Ministério da Educação. Conselho Nacional. Resolução CNE/CEB $n^{\circ} 5$, de 17 de dezembro de 2009. Fixa as Diretrizes curriculares nacionais para a educação infantil. Conselho Nacional de Educação. Diário Oficial da União. Brasília: 18 dez. 2009.

BRASIL. Ministério da Educação. Diretrizes Curriculares Nacionais para a Educação Escolar Indígena. MEC/SECAD, 2012.

BRASIL. Políticas Públicas em Educação junto às populações rurais, indígenas e de fronteira no Brasil: avanços e desafios. MEC/SECAD, Coordenação de Educação Escolar Indígena, s/d, mimeo (2).

CHAUÍ, Marilena. Convite à filosofia. São Paulo: Ática, 2001.

"Vida e Obra". In: ROUSSEAU, Jean Jacques. Discurso sobre a origem e os fundamentos da desigualdade entre os homens. (Apresentação, vida e obra de Marilena CHAUÍ) São Paulo, Abril Cultural, 1978 (Coleção Os Pensadores) CHAWLA, Louise. Childhood place attachments. In: I. Altman \& S. Low (Eds), Place Attachment, New York: Plenum, 1992.

DELEUZE, Gilles. Espinosa, filosofia prática. São Paulo: Escuta, 2002. 
ESPINOSA, Baruch de. Ética. São Paulo, Abril Cultural, 1983. (Coleção Os Pensadores).

FERNANDES, Florestan. Notas sobre a educação na sociedade tupinambá. In: FERNANDES, F. A investigação etnológica no Brasil e outros ensaios. Petrópolis: Vozes, 1975, pp. 33-83.

FÉLIX, Cláudio. Uma escola para formar guerreiros. Irecê-BA: Print Fox, 2007.

FLORES, Maria Luíza; TIRIBA, Léa. A educação infantil no contexto da Base Nacional Comum Curricular: em defesa das crianças como seres da natureza, herdeiras das tradições culturais brasileiras. Debates em Educação, Maceió, v. 8, n. $16, \quad$ p. $157-183, \quad$ jul./dez. $2016 . \quad$ Disponível em: <http://www.seer.ufal.br/index.php/debateseducacao/issue/view/213/showToc> Acesso em: 15.out. 2017.

FORMOSINHO, Júlia (Org.). Modelos Curriculares para a Educação da infância. Lisboa: Porto Editora, 1998.

GALLO, Silvio. Deleuze e a Educação. Belo Horizonte, Autêntica, 2003.

GEERTZ, Cliffort. A interpretação das culturas. Rio de Janeiro: Guanabara, 1989.

GLEIZER, Marcos. Espinosa e a afetividade humana. Rio de Janeiro: Jorge Zahar, 2005.

GUATTARI, Félix. As três ecologias. Campinas: Ed. Papirus, 1990.

GUIMARÃES, Mauro e PRADO, Carlos. Educação em Direitos Humanos e ética ambiental. IN: SILVA, Aida. M. M., e TIRIBA, Léa. (Orgs.). Direito ao ambiente como direito à vida: desafios para a educação em Direitos Humanos. SP: Cortez, 2014.

KELLERT, Stephen; WILSON, Edward. The Biophilia Hypothesis. Washington: Island Press; 1993.

LOUREIRO, Carlos Frederico Bernardo. Sustentabilidade e Educação: um olhar da ecologia política. São Paulo: Cortez, 2012.

MATURANA, Humberto. Emoções e linguagem na educação e na política. Belo Horizonte: Ed. UFMG, 2002.

NÖTZOLD, Ana Lúcia Vulfe. Cotidiano e Educação dos Jovens Tupinambá. Revista Virtual de Ciências Humanas IMPRIMATUR - Ano 1 No. 3. Disponível em http://www.cfh.ufsc.br/imprimat/nr.3/pdf/tupinamba.pdf.

PLASTINO, Carlos Alberto. Subjetividade e educação. 1994. mimeo.

PROFICE, Christiana Cabicieri. Percepção ambiental infantil em ambientes naturais protegidos. $2010.180 \mathrm{f}$. Tese (Doutorado em Psicologia, Sociedade e Qualidade de Vida) - Universidade Federal do Rio Grande do Norte, Natal, 2010.

. Crianças e Natureza, Reconectar é preciso. São Paulo: Pandorga, 2016.

ROSEMBERG, F. Educação Infantil e povos indígenas no Brasil: apontamentos para um debate. In: Discutindo políticas de Educação Infantil e educação escolar indígena. MIEIB/Centro de Cultura Luiz Freire, s/d.

SANTOS, Boaventura de Souza. A crítica da razão indolente: contra o desperdício da experiência. São Paulo: Cortez, 2001.

SANTOS, Gabriel Moreira; ALMEIDA, Nathane dos Anjos; PROFICE, Christiana Cabicieri. As brincadeiras entre crianças Tupinambá de Olivença: tradições passadas por gerações. Zero-a-Seis, v. 16, n. 30 p. 259-274, 2014.

SILVA, Aida; TIRIBA, Léa. (Orgs.). Direito ao ambiente como direito à vida: desafios para a educação em Direitos Humanos. São Paulo: Cortez, 2014.

TIRIBA, Léa. Crianças, natureza e educação infantil. 2005. 249 f. Tese (Doutorado em Educação) - Pontifícia Universidade Católica do Rio de Janeiro, Rio de Janeiro, 2005. 
Educação entre os povos Tupinambá de Olivença. Projeto tendências de Políticas de Transição em comunidades rurais, indígenas e de fronteira. Estudo de caso Brasil. Brasília. OEA/MEC/COEDI/Fundação Bernard Van Leer, 2010.

. Educação Infantil como Direto e Alegria. Revista Laplage, V. 3, série 1, p.72. São Carlos, São Paulo, PPGEUFSCar, 2017. Disponível em: 〈http://www.laplageemrevista.ufscar.br/index.php/lpg/article/view/248 > Acesso em: 15.out. 2017

TIRIBA, Léa; PROFICE, Christiana Cabicieri. Interações afetivas e apego à natureza. In: REIS, M.; XAVIER, M. C.; SANTOS, L. (Orgs.). Crianças e Infâncias: educação, conhecimento, cultura e sociedade. São Paulo: Annablume, 2012.

TIRIBA, Léa; PROFICE, Christiana Cabicieri. O direito humano à interação com a natureza. In: SILVA, Aida; TIRIBA, Léa. (Orgs.). Direito ao ambiente como direito à vida: desafios para a educação em Direitos Humanos. São Paulo: Cortez, 2014.

VYGOTSKY, L.S. A Formação Social da Mente. RJ, Martins Fontes, 1989. 


\section{CRIANÇAS TUPINAMBÁ: RIOS, COLINAS, BANCOS DE AREIA E MATAS COMO LUGARES DO BRINCAR COTIDIANO}

RESUMO

O texto apresenta resultados de pesquisa-intervenção sobre processos de escolarização indígena entre povos Tupinambá de Olivença, em especial no que diz respeito às interações afetivas e apego à natureza. Orientam a investigação concepções de Espinosa e Guatarri, bem como conceitos do campo de estudos pessoaambiente, tais como apego ao lugar e biofilia. Análises parciais revelam que as brincadeiras com a natureza ocupam posição de destaque na vida infantil; que as práticas escolares fortalecem sentimentos de pertencimento ao mundo natural e a inventividade das crianças, criadoras de seus próprios artefatos; e que os núcleos Tupinambá de Educação Infantil poderão inspirar pedagogias comprometidas com a escuta das crianças e a proteção de todas as formas de vida, não apenas a humana.

Palavras-chave: Crianças Tupinambá. Educação Escolar Indígena. Brincadeiras com a Natureza.

\section{TUPINAMBÁ CHILDREN: RIVERS, HILLS, SAND BANKS AND FOREST AS PLACES OF EVERYDAY PLAYING} ABSTRACT

The text present reaserch - intervention results on the process of indigenous schooling among the Tupinambá people of Olivença, especially with respect to affective interactions and attachment to nature. They guide the investigation of Espinosa and Guatarri conceptions, as well as concepts from the field of human-environment studies, such as attachment to place and biofilia. Partial analyzes reveal that play with nature occupies a prominent position in children's lives; that school practices strengthen feelings of belonging to the natural world and the inventiveness of children, creators of their own artifacts; and that the Tupinambá nuclei of Early Childhood Education may inpire pedagogies committed to listening children and protecting all forms of life, not just human life.

KeyWords: Tupinambá Children. Indigenous School Education. Nature's Play.

\section{NIÑOS TUPINAMBÁ: RIOS, COLINAS, BANCOS DE ARENA Y MATAS COMO LUGARES DEL BRINCAR COTIDIANO}

RESUMEN

El texto presenta resultados de investigación-intervención sobre procesos de escolarización indígena entre los Tupinambá de Olivenza, referente a las interacciones afectivas y apego a la naturaleza. La investigación la orientan concepciones de Espinosa y Guatarri, así como conceptos del campo de estudio persona-ambiente, tales como apego al lugar y biofilia. Análisis parciales revelan que los juegos con la naturaleza se destacan en la vida infantil; que las prácticas escolares fortalecen sentimientos de pertenencia al mundo natural y a la inventiva de los niños, creadora de sus propios artefactos; y que los núcleos Tupinambá de Educación Infantil podrán inspirar pedagogías comprometidas con la escucha de los niños y la protección de todas las formas de vida, no sólo la humana.

Palabras clave: Niños Tupinambá. Educación Escolar Indígena. Juguetes con la Naturaleza. 